\title{
The Input-0utput Transformation of the Hippocampal Granule Cells: From Grid Cells to Place Fields
}

\author{
Licurgo de Almeida, ${ }^{1}$ Marco Idiart, ${ }^{1,2}$ and John E. Lisman ${ }^{3}$ \\ ${ }^{1}$ Neuroscience Program and 2 Physics Institute, Universidade Federal do Rio Grande do Sul, Porto Alegre 91501-970, Brazil, and ${ }^{3}$ Department of Biology and \\ Volen Center for Complex Systems, Brandeis University, Waltham, Massachusetts 02454
}

Grid cells in the rat medial entorhinal cortex fire (periodically) over the entire environment. These cells provide input to hippocampal granule cells whose output is characterized by one or more small place fields. We sought to understand how this input-output transformation occurs. Available information allows simulation of this process with no freely adjustable parameters. We first examined the spatial distribution of excitation in granule cells produced by the convergence of excitatory inputs from randomly chosen grid cells. Because the resulting summation depends on the number of inputs, it is necessary to use a realistic number $(\sim 1200)$ and to take into consideration their 20 -fold variation in strength. The resulting excitation maps have only modest peaks and valleys. To analyze how this excitation interacts with inhibition, we used an E\%-max (percentage of maximal suprathreshold excitation) winner-take-all rule that describes how gamma-frequency inhibition affects firing. We found that simulated granule cells have firing maps that have one or more place fields whose size and number approximates those observed experimentally. A substantial fraction of granule cells have no place fields, as observed experimentally. Because the input firing rates and synaptic properties are known, the excitatory charge into granule cells could be calculated $(2-3 \mathrm{pC})$ and was found to be only somewhat larger than required to fire granule cells ( $1 \mathrm{pC})$. We conclude that the input-output transformation of dentate granule does not depend strongly on synaptic modification; place field formation can be understood in terms of simple summation of randomly chosen excitatory inputs, in conjunction with a winner-take-all network mechanism.

\section{Introduction}

The process by which neurons transform their inputs into outputs is fundamental to understanding brain function but has been difficult to study. Information must be available about the number of excitatory synaptic inputs to target neurons, their synaptic strength, and their receptive field properties. Information must also be available about the inhibition that interacts with excitation. These types of information are generally not available.

One brain region where there is sufficient information is the monosynaptic connection of layer 2 cells of the medial entorhinal cortex with the granule cells of the dentate gyrus, the main input region of the hippocampus. Cells in this region of the brain fire in a way that depends on the position of the animal. The inputoutput transformation is remarkable. Entorhinal cells respond to evenly spaced positions over the entire environment and have therefore been termed grid cells (Hafting et al., 2005; Sargolini et al., 2006). Different grid cells have different phase and spatial frequency. In contrast, granule cells respond only to one or a few positions and have therefore been termed "place cells" (O’Keefe,

Received Dec. 19, 2008; revised March 24, 2009; accepted April 26, 2009.

This work was supported by National Institute of Mental Health Grant MH060450 and National Institute of Neurological Disorders and Stroke Grant NS27337 and European Commission Project 217148. Marco Idiart and Licurgo de Almeida acknowledge partial financial support from Brazilian agencies Conselho Nacional de Desenvolimento Científico e Tecnológico and Coordenação de Aperfeiçoamento de Pessoal de Nível Superior.

Correspondence should be addressed to John E. Lisman, Department of Biology and Volen Center for Complex Systems, Brandeis University, 145 South Street, Waltham, MA 02454. E-mail: Lisman@Brandeis.edu.

DOI:10.1523/JNEUROSCI.6048-08.2009

Copyright $\odot 2009$ Society for Neuroscience $\quad$ 0270-6474/09/297504-09\$15.00/0
1976; Leutgeb et al., 2007). Several fundamental questions may be asked about this transformation: (1) Does this transformation require learning or can it be accounted for by fixed properties of the system? (2) Is the transformation done at the level of individual cells or are network processes involved? (3) Does the exact number of synaptic inputs and their strength matter, or can the transformation be analyzed in a simplified system? (4) Is the absolute level of excitation much greater than threshold (and balanced by a large inhibition), or is excitation on the same order as threshold?

Fortuitously, extensive investigation of this brain region provides all the information necessary to analyze the input-output transformation of dentate granule cells. First, the connections between the entorhinal cortex and granule cells have been anatomically analyzed and the number of inputs is known (Nafstad, 1967; Hama et al., 1989; Johnston and Amaral, 1998). Second, the size, release probability, and quantal size of synapses of layer 2 entorhinal cells onto granules cells has been determined (Trommald and Hulleberg, 1997; Bekkers and Clements, 1999), allowing quantitative assessment of synaptic strength and its variability. Third, properties of inhibition have been studied; notably, the observation that cells fire phase locked to gamma oscillations (Bragin et al., 1995; Csicsvari et al., 2003) indicates that gammafrequency inhibition is a major determinant of cell firing. Finally, the firing threshold properties of the postsynaptic granule cells have been determined (Geiger and Jonas, 2000). Together, this data set provides the basis for analyzing the input-output transformation in this system. This goal is aided by the development of 

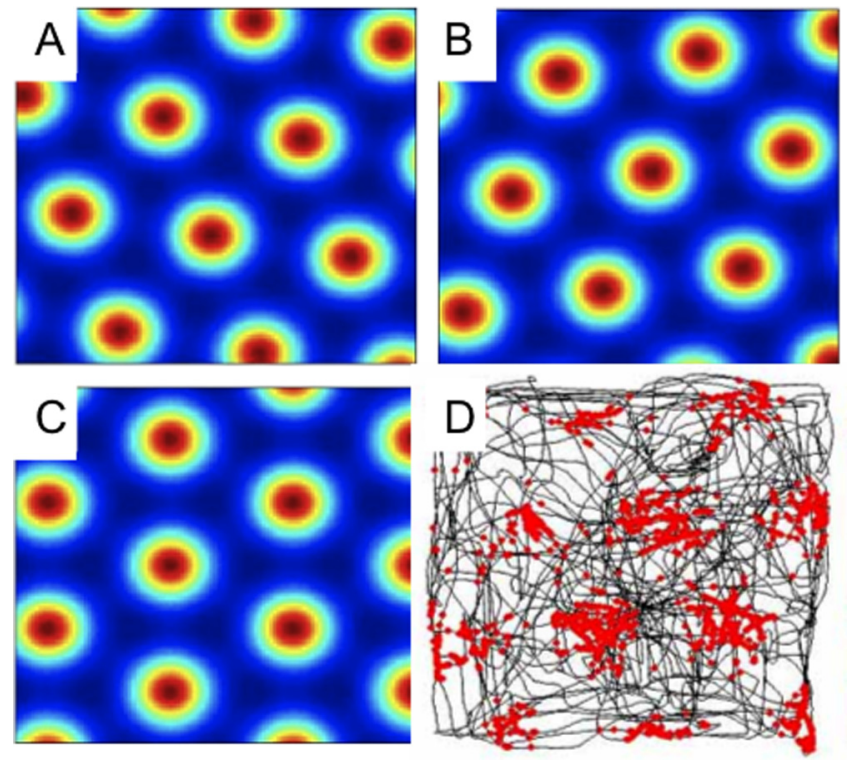

Figure 1. The receptive fields of grid cells have three different orientations. $\boldsymbol{A}-\boldsymbol{C}$, Three examples show the possible orientation of grid cells in our simulations. $\boldsymbol{D}$, An example of an actual grid cell from Sargolini et al. (2006); dots are spikes; lines are the path of the rat.

a framework for describing the computational role of gamma frequency inhibition (de Almeida et al., 2009). An important aspect of this framework is that the winner-take-all process that is performed by gamma oscillations does not depend strongly on the exact magnitude of inhibition and can therefore be applied when this magnitude is not known. We are thus able to analyze the formation of place fields with no freely adjustable parameters.

\section{Materials and Methods}

Grid cells. Activity maps of simulated grid cells and place cells were represented by a square matrix of bins, each bin representing an area of 1 $\mathrm{cm}^{2}$ in a $1 \times 1 \mathrm{~m}$ square environment. To simulate the activity of grid cells, we used the expression developed by Blair et al. (2007) according to which the rate at spatial location $r=(x, y)$ is as follows:

$$
G(r, \lambda, \theta, c)=g\left(\sum_{k=1}^{3} \cos \left(\frac{4 \pi}{\sqrt{3 \lambda}} u\left(\theta_{k}+\theta\right) \cdot(r-c)\right)\right),
$$

where $\mathrm{u}\left(\theta_{\mathrm{k}}\right)=\left(\cos \left(\theta_{\mathrm{k}}\right), \sin \left(\theta_{\mathrm{k}}\right)\right)$ is the unitary vector pointing to the direction " $\theta_{\mathrm{k}}$." Each cosine in Equation 1 establishes a pattern of alternating maxima and minima in the direction " $\theta_{\mathrm{k}}$." The combined sum of the three patterns at angles $\theta_{1}=-30^{\circ}, \theta_{2}=+30^{\circ}$, and $\theta_{3}=+90^{\circ}$ is a honeycomb grid with intervertex spacing equal to $\lambda$. The angle $\theta$ is an arbitrary rotation that we assume to be either $\theta=0^{\circ}, 20^{\circ}$, or $40^{\circ} . c=\left(x_{0}\right.$, $\left.y_{0}\right)$ is the spatial phase of the grid. The resulting grid orientations are illustrated in Figure $1 A-C . g$ is a monotonically increasing gain function given by $g(x)=\exp [a(x-b)]-1$. The parameter $b$ was set to $-3 / 2$ so that the minimal firing rate is zero, since the summation of the three cosine functions has a minimum value of $-3 / 2$. The parameter $a$ was chosen to be 0.3 to make the spatial decay from the center of each vertex match the experimentally observed decay (Leutgeb et al., 2007), as demonstrated in Figure 2.

Granule cells. In our model, granule cells receive excitatory input from randomly chosen grid cells. The place cells that are active for a given position in the environment are then determined according to the interaction of the summed excitation and inhibition using a rule based on the percentage of maximal suprathreshold excitation (E\%-max) winnertake-all process (see below).

The excitatory input received by the $i$ th place cell from the grid cells is given by Equation 2:

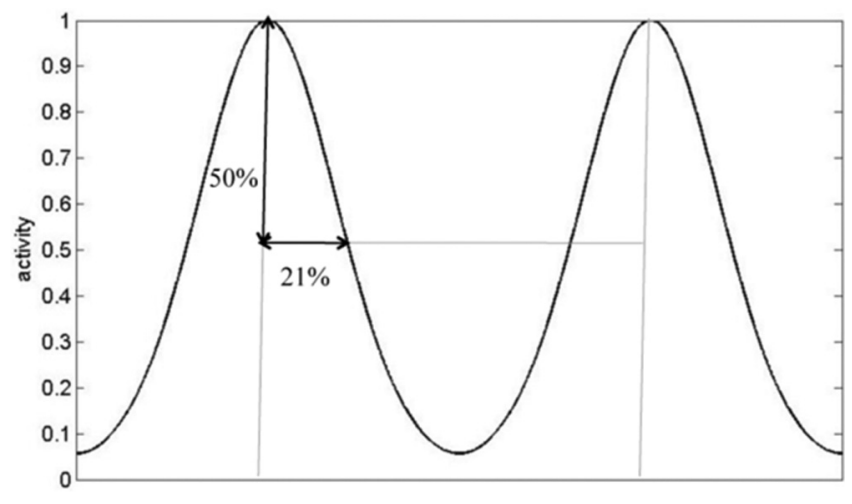

Figure 2. Firing rate as a function of distance between the vertices of grid cells. We used Equation 1 to define this spatial decay of activity from the vertices (maximum activity) and matched this decay to that measured in (Leutgeb et al., 2007) (values here are normalized to the intervertex distance). Firing rate falls to $50 \%$ at a distance that is $21 \%$ of the intervertex distance. This condition is met for $a=0.3$. At the half point between vertices there is $\sim 8 \%$ activity; the true minima is even lower, but not located along this line.

$$
I_{\text {grid }}^{i}(r)=\sum_{j-1}^{n_{\text {grid }}} W_{i j} G_{j}(r),
$$

where $W_{i j}$ is the synaptic weight of each input. $W_{i j}$ can be either 0 (no connection) or a positive random value distributed according to a function described below.

The activity of the $i$ th place cell is given by the following:

$$
F_{\text {place }}^{i}(r)=I_{\text {grid }}^{i}(r) \cdot H\left(I_{\text {grid }}^{i}(r)-(1-k) \cdot \max _{\text {grid }}(r)\right),
$$

where the range of $k(0.05-0.15)$ was as estimated in our companion paper (de Almeida et al., 2009). Specifically, $k$ (referred to as E\%-max) determines which cells fire according to the following rule: cells fire if their feedforward excitation is within $E \%$ of the cell receiving maximal excitation. We assume here that $E$ is very close to total excitation; this is a reasonable approximation given the results computed at the end of the Results section. $I_{\text {grid }}^{\max }(r)$ is the maximum input received by a place cell for the position $r . H(x)$ is the Heaviside function, where $H(x)=1$ if $x>0$ and is 0 otherwise.

Distribution of synaptic weights. We have used the measured size distribution of excitatory synapses onto granules cells (Trommald and Hulleberg, 1997) to a fit a function for this distribution:

$$
P(s)=A\left(1-e^{-\left(\frac{s}{\sigma_{1}}\right)}\right)\left(e^{-\left(\frac{s}{\sigma_{2}}\right)}+B \cdot e^{-\left(\frac{s}{\sigma_{3}}\right)}\right),
$$

where $s$ is the synaptic area (in square micrometers). $s$ ranges from 0 to $0.2 \mu \mathrm{m}^{2}$ and $A=100.7, B=0.02, \sigma_{1}=0.022 \mu \mathrm{m}^{2}, \sigma_{2}=0.018 \mu \mathrm{m}^{2}$, and $\sigma_{3}=0.15 \mu \mathrm{m}^{2}$. Synaptic weight is related to synapse size through the relationship:

$$
W(s)=\frac{s}{0.2}\left(\frac{s}{s+0.0314}\right) .
$$

The first term expresses the linear dependence of quantal release probability on synapse area (for justification, see Results); the second term shows how quantal size depends on synapse area. The area, which produces a quantal current that is half that at the largest synapses $\left(0.2 \mu \mathrm{m}^{2}\right)$, is $0.0314 \mu \mathrm{m}^{2}$. This value was calculated according to the model of Raghavachari and Lisman (2004), which correctly predicts the rise-time, amplitude, and variance of the quantal response. We thank Sridhar Raghavachari (Duke University, Durham, NC) for using this model to systematically vary synapse size and thereby determine the 0.0314 value.

Analysis of place fields. To compare real data with the place fields produced by our model, two measures were adopted: number of place fields, i.e., the number of regions in the recorded area that met the criterion for a place field (see below), and the size of these place fields. The environ- 


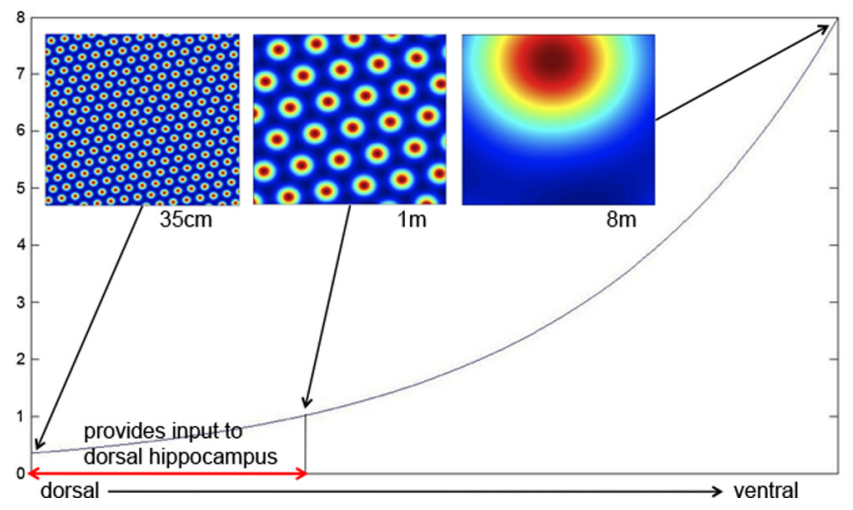

Figure 3. The spatial frequency of grid cells as a function of distance along the dorsoventral axis of the entorhinal cortex. According to Hafting et al. (2005), the intervertex distance varies from $\approx 35 \mathrm{~cm}$ in the most dorsal region to $\approx 8 \mathrm{~m}$ in more ventral regions (the most ventral region has not been recorded from). Granule cell recordings are from the dorsal hippocampus; based on anatomical results showing that this region receives input from only part of the entorhinal cortex, we estimate that the grid cells that provide input to granule cells have a spacing that varies from $35 \mathrm{~cm}$ to $1 \mathrm{~m}$ (two-headed arrow near bottom) (see Results).
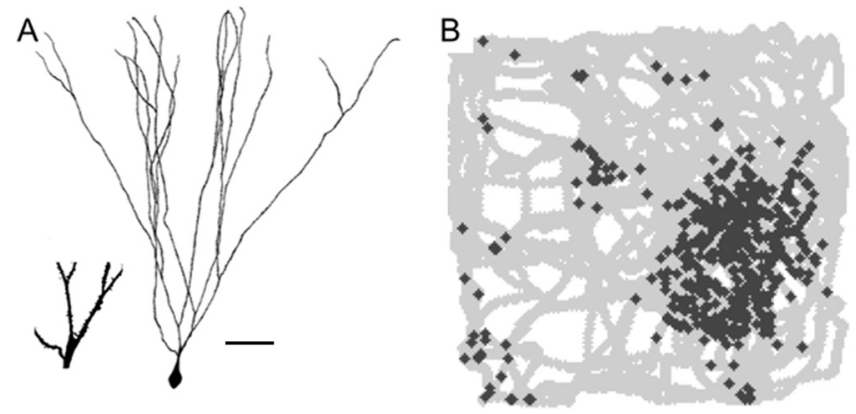

Figure 4. Morphology and receptive field properties of dentate granule cell. $\boldsymbol{A}$, Camera lucida drawing of a rat granule neuron adapted from Rahimi and Claiborne (2007). Scale bar, 5 $\mu \mathrm{m}$. Inset shows magnified region on which spines can be seen. $\boldsymbol{B}$, Activity (marked by + signs) of a dentate granule cell in a $1 \mathrm{~m}$ by $1 \mathrm{~m}$ square box. Twisting lines indicate path of rat through the box. There are several place fields; adapted from Leutgeb et al. (2007).

ment for real and simulated data was $1 \mathrm{~m}$ by $1 \mathrm{~m}$. Following the definition of this (Muller and Kubie, 1989), a place field was defined as a continuous region of at least $200 \mathrm{~cm}^{2}$ consisting of bins that exceed a firing rate of $20 \%$ of the cell's peak firing rate. The number of place fields and their average area were calculated using simple image recognition programs implemented specially for these simulations. The experimental data on dentate place fields was obtained from (Leutgeb et al., 2007).

All computations were performed using the Matlab programming language (MathWorks).

\section{Results}

Grid cells in layer 2 of the medial entorhinal cortex have widely varying spatial frequency ranging from $30 \mathrm{~cm}$ to over $8 \mathrm{~m}$ (Fig. 3). This variation in frequency is systematically mapped along the dorsal ventral axis of the entorhinal cortex (Hafting et al., 2005). Grid cells make monosynaptic connections onto granule cells of the dentate gyrus (Fig. 4A). These cells do not have grid-like receptive fields, but rather have one or a few place fields (Fig. $4 B$ ). The overall question we address is how this transformation occurs.

To determine the range of spatial frequencies that provide input to a granule cell, it is necessary to account for the fact that the region of dentate gyrus from which recordings are made receives input from only part of the dorsoventral axis of the medial entorhinal cortex. The region of the dentate where recordings have been made receives input from $\sim 1 / 4$ of this axis (Witter, 2007) (M. Witter, personal communication). The region of the largest recorded grid-cell spacing $(8 \mathrm{~m})$ is only $60 \%$ along the entire axis. Based on these facts (and the assumption of logarithmic mapping), we estimate that the spatial frequency of inputs to recorded granule cells varies from $35 \mathrm{~cm}$ to $1 \mathrm{~m}$ (Fig. 3, twoheaded arrow near bottom).

We next estimated the number of synapses made by grid cells onto granule cells. The dendritic region of dentate granule cells is divided into three layers. In the rat, it is the middle layer that receives input from grid cells (for review, see Witter, 2007). According to Johnston and Amaral (1998), granule cells have $\sim 3000 \mu \mathrm{m}$ of dendrite and the spine density is 2.3 spines/micrometer. There are thus $\sim 6840$ spines, each of which contains one synaptic input. Approximately $30 \%$ of these are in the middle molecular layer (Hama et al., 1989), where the layer 2 cells form synapses. Of the synapses in this region, $\sim 85 \%$ receive input from layer 2 of the entorhinal cortex (Nafstad, 1967). But not every cell in layer 2 is a grid cell; Sargolini et al. (2006) indicate that only $72 \%$ of the cells in this layer have well defined grid fields. Taking all this information into consideration yields a total of 1200-1300 spines on the granule cell that have synaptic inputs from grid cells. The results of Min et al. (1998) indicate that the fraction of silent synapses is small in this cell type; we therefore take 1200 as the number of nonsilent synapses made by grid cells onto granule cells.

\section{Excitatory drive to granule cells}

To determine the excitatory drive to a granule cells from grid cells, we used a brute force procedure. We made a library of 10,000 grid cells, each with a different spatial frequency (varying from $35 \mathrm{~cm}$ to $1 \mathrm{~m}$ ), phase, and orientation (see Materials and Methods). We then made 1200 random selections from the library and summed them, yielding an excitation map, one of which is illustrated in Figure $5 A$. In these initial simulations, each synapse was assumed to have the same synaptic strength. Figure $5 B$ shows the excitation map if we summed a smaller number (300) of grid cell inputs. It can be seen that the spatial modulation of the normalized excitation map is much less with 1200 inputs than with 300 inputs, as would be expected from an averaging process. This comparison underscores the importance of quantitatively accounting for the inputs to granule cells.

These considerations prompted us to consider not only the number of input synapses, but also their differing synaptic weights. Clearly if some synapses are almost silent, they will contribute little, thus lowering the effective number of synaptic inputs. It is thus important to take into account the variability of synaptic strengths of grid cell inputs. Morphological analysis indicates that, as in most brain region, the size of synapses onto dentate granule cells is highly variable (Trommald and Hulleberg, 1997). Recent physiological work strongly argues that synaptic strength and size are related. Specifically, the number of postsynaptic receptors (AMPAR) is proportional to synapse area (Nusser et al., 1998) and therefore to spine size (Lisman and Harris, 1993). Furthermore, the AMPA current evoked by local two-photon uncaging of glutamate is proportional to spine size (Matsuzaki et al., 2001). Finally, during long-term potentiation (LTP), spine size and synapse size increase (Harris et al., 2003; Matsuzaki et al., 2004), whereas during long-term depression, spine size decreases (Zhou et al., 2004) (the effect on synapse size has not been determined).

We base our estimate of the strength distribution of dentate synapses on the size distribution of synapses (Fig. $6 B$ ), as deter- 

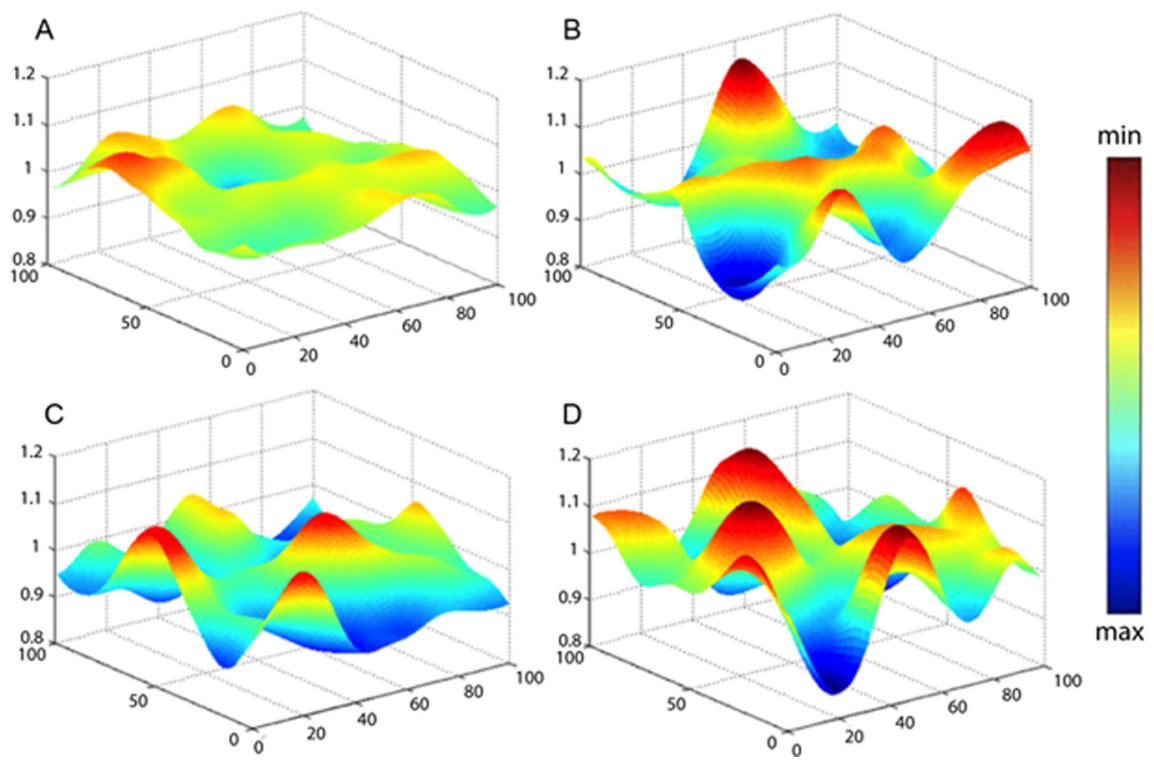

Figure 5. Excitation maps in granule cells normalized to the average excitation. The typical excitation maps for different input configurations: $A$, Equal synaptic weights from 1200 grid cells. $\boldsymbol{B}$, Equal synaptic weights from 300 grid cells. C, D, Two examples with input from 1200 grid cells, but with synaptic weights varying according to the distribution in Figure $6 B$.
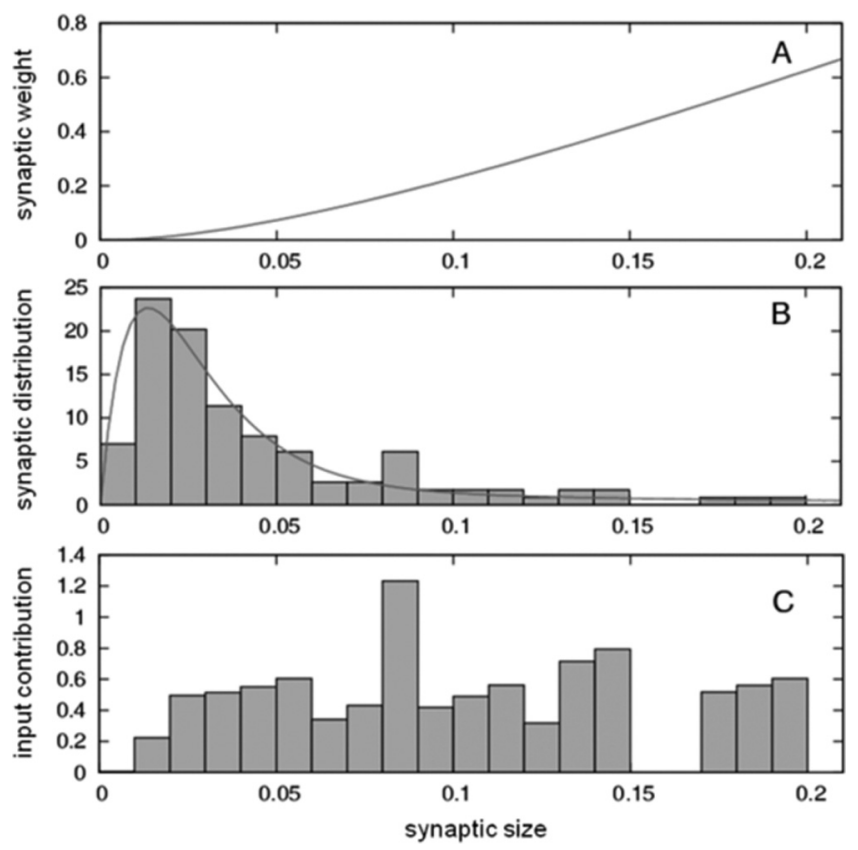

Figure 6. Synaptic weight and contribution as a function of synpapse size. $A$, Relationship between synaptic weight and synapse size (in square micrometers) according to Equation 5 (see Materials and Methods and Results). $\boldsymbol{B}$, Comparison between the analytical expression derived to describe the size distribution of synapses (line) and the experimental data (bars) (Trommald and Hulleberg, 1997). C, Input contribution (synaptic weight multiplied by the fraction of synapses of that size) as a function of size.

mined by serial section electron microscopy (Trommald and Hulleberg, 1997). These data show that synapse size varies over a 20 -fold range. We developed an equation for calculating relative synaptic strength from spine size, as follows. Synaptic strength is the product of quantal size and quantal content. Quantal size is relatively invariant with synapse size (Raghavachari and Lisman, 2004; Lisman et al., 2007); quantal size falls only if a synapse is smaller than the $100 \mathrm{~nm}$ radius hotspot of AMPA channel activation produced by the glutamate released from a single vesicle, as described by the second term in Equation 5 . The probability of release has been demonstrated to be proportional to the readily releasable pool, which has been identified as docked vesicles (Murthy et al., 2001). The number of docked vesicles is proportional to synapse area (Schikorski and Stevens, 1997). Therefore, the number of vesicles released is expected to be proportional to synapse size. Taking this size dependence of quantal size and quantal release probability into consideration, we derived Equation 5 for the dependence of synaptic strength on synapse size (Fig. $6 A$ ).

In passing, we note that small synapses are numerous (Fig. $6 \mathrm{~B}$ ) but weak, whereas large synapses are few but strong; when the "excitatory input contribution" (product of number of synapses and their strength) is plotted, it is nearly invariant with synapse size (Fig. 6C). This is a surprising result and could reflect some unknown principle that controls the distribution of synaptic strength.

Given the development of an expression for the variation in synaptic strength (Fig. 6A), we could calculate the effect of 1200 realistic inputs to granule cells. We computed excitation maps by choosing 1200 grid cells at random, but also assigning synaptic strength at random according to the measured distribution of synapse size. This yielded excitation maps such as the two examples shown in Figure 5, $C$ and $D$. By comparing these graphs to Figure $5 A$, it can be seen that taking into consideration the variability of synaptic strength has as a major effect on excitation maps (increases the spatial variation).

\section{Interaction of excitation and inhibition}

We next considered how excitation and inhibition interact to produce place fields. Extracellular recordings from the dentate gyrus show prominent gamma frequency oscillations (Bragin et al., 1995; Csicsvari et al., 2003). Such oscillations arise at least in part through excitation of interneurons by granule cells and feedback inhibition back onto the granule cells (Sik et al., 1997; Bartos et al., 2002; Mann et al., 2005). To simulate the formation of place fields in granule cells, it is therefore necessary to account for the interaction of gamma frequency inhibition with the excitation maps. We used a framework developed in a previous study (de Almeida et al., 2009). According to this framework, as inhibition declines during a gamma cycle, the most excited cell fires first. This triggers rapid global feedback inhibition. However, because there is a few millisecond delay in this feedback, other slightly less excited cells will fire during this delay. In contrast, because there remains significant inhibition during the delay, many cells with substantial excitation will not reach threshold. The overall process can be described as an $E \%$-max winner-take-all process: at each point in space, all cells that have excitation that is within $E \%$ of the cell with maximal excitation will fire. The value of $E \%$-max is approximated by the ratio $d / \tau$, where $d$ is the delay between the time of a granule cell spike and the onset of the consequent feedback inhibition. Based on physiological studies in CA1, $d$ is 2-3 $\mathrm{ms}$ (Miles, 1990) and appears to be similar in the dentate (Geiger et al., 1997; Kraushaar and Jonas, 2000; Alle et al., 2001). $\tau$ is the membrane time constant, which is $\sim 30 \mathrm{~ms}$ in granule cells 


\section{(A) $\mathrm{E} \%-\max =10 \%$}
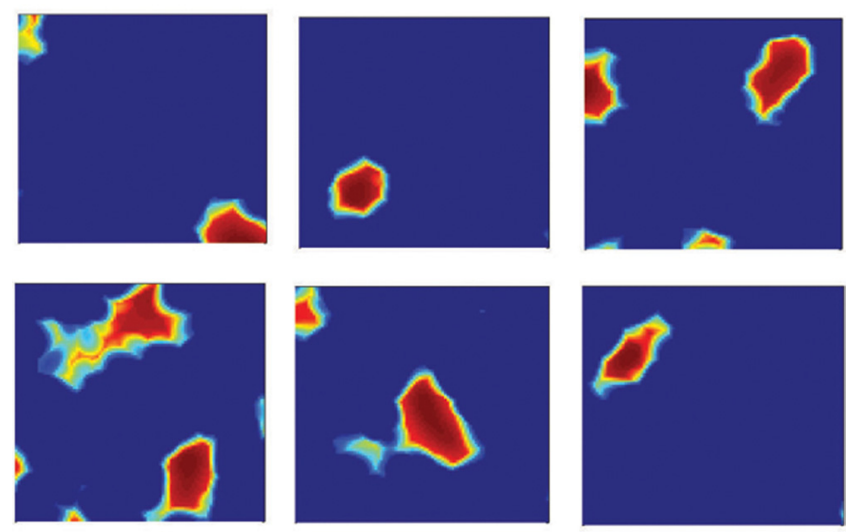

(B) Experimental data
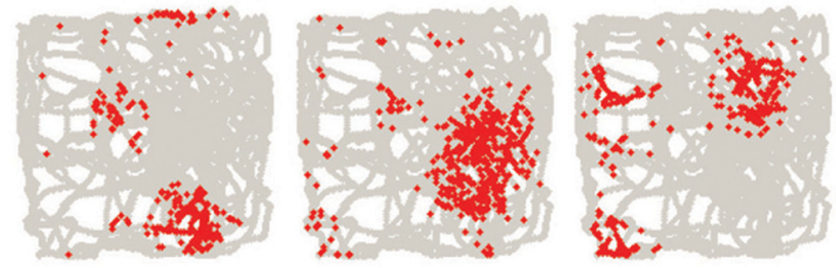

Figure 7. Comparison of computed granule cell place fields to experimentally observed fields. $\boldsymbol{A}$, Different examples of the computed spatial firing of different granule cells (E\%-max $=$ 10\%). $\boldsymbol{B}$, Granule cell place fields measured by Leutgeb et al. (2007).

(Schmidt-Hieber et al., 2008). Thus, $E \%$-max is $\sim 10 \%$. The ratio of inhibition to excitation in the dentate gyrus is not known; it is therefore fortunate that $E \%$-max does not depend on the exact value of this ratio (de Almeida et al. 2009).

The E\%-max computation involves competition between granule cells, i.e., it is a network process. To calculate place fields, it is therefore necessary to simulate the interaction of many granule cells. To do this, we constructed an excitation map for 10,000 granule cells and implemented the $E \%$-max rule at each point in space. This was done by finding the cell with maximal excitation, as well as all cells with excitation at least $10 \%$ of this maximal value. These cells were considered to fire at a rate proportional to the degree of suprathreshold excitation. We then plotted the receptive fields of granule cells, with a color code representing firing rate (dark red represents maximum activity; dark blue minimum activity). The resulting place field properties were then compared with experimental data. According to our analysis of the experimental data (see Materials and Methods), the average granule cells has 2.2 place fields and the average area of each place field $=$ $667.3 \mathrm{~cm}^{2}[n=13$ based on examples of place fields from (Leutgeb et al., 2007)]. In our simulations, granule cells had an average of 1.5 place fields and these had an average area of $627 \mathrm{~cm}^{2}$ (Fig. $7 B)$. Given the somewhat arbitrary criteria for defining place fields and the small amount of experimental data available (13 place fields), the agreement between simulation and experiment (Fig. $7 A$ ) is quite reasonable. Although the value of $E \%$-max $=$ $10 \%$ used in these simulation is supported experimentally (see above), we have examined somewhat larger and smaller values. If $E \%-\max =5 \%$, the average number of place fields $=1.2$ and their average area $=367 \mathrm{~cm}^{2}$; if $E \%$-max $=15 \%$, the average number of place fields $=2.1$ and their average area $=1311 \mathrm{~cm}^{2}$.

Recent experimental work indicates that only a small fraction $(2-8 \%)$ of dentate granule cells show c-Fos activation in a given environment (Chawla et al., 2005; Ramirez-Amaya et al., 2006;

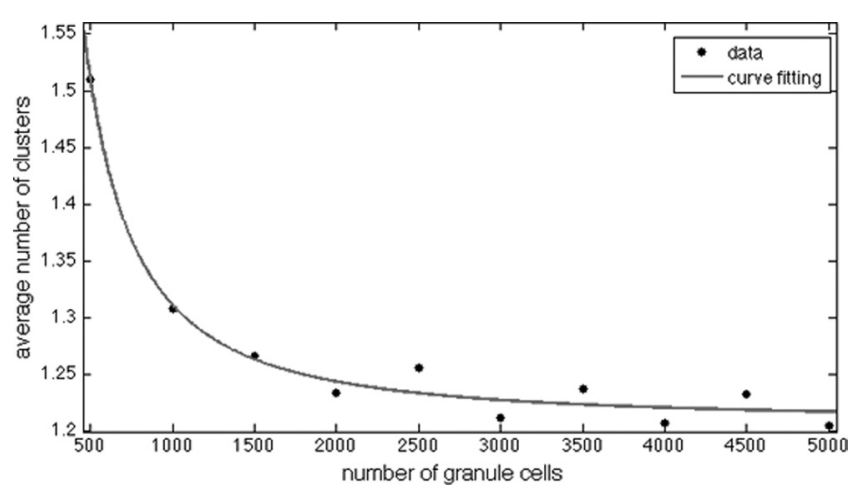

Figure 8. Average number of computed place fields as function of the number of granule cells used in the simulations. Each cell here is connected to $1200 \mathrm{grid}$ cells with equal weights. As the number of granule cells is increased, the average number of place fields reaches an asymptotic value.

Tashiro et al., 2007). Although c-Fos activation reflects plasticity processes rather than firing per se (and thus provides a lower limit estimate of number of cells that have place fields), the low fraction of cells showing c-Fos activation still suggests that many granule cells do not have place fields. Consistent with this, we found that with $E \%$-max $=10 \%$, only $25 \%$ of simulated granule cells had place fields (for $E \%$ - $\max =5 \%, 3 \%$ had place fields; for $E \%-\max =15 \%, 74.5 \%$ had place fields). We conclude that the competitive process is such that a substantial fraction of granule cells will never be winners.

Recent experiments show that although only a small fraction of granule cells have place fields, $85 \%$ of granule cells active in one environment will also be active in another (Leutgeb et al., 2007) [see related findings by Chawla et al. (2005) and Tashiro et al. (2007)]. We wondered whether part or all of this effect might simply result because, by chance, these cells had greater average synaptic strength than others. To explore this hypothesis, we implemented "different environments" by assuming that the changes in the entorhinal cortex from one environment to another randomly reshuffled (remapped) the properties of grid cells. We simulated 4500 granule cells, each getting input from 1200 grid cells. If granule cells retained their synaptic strengths, $63.5 \%$ of granule cells had place fields in both environments. In contrast, if we eliminated synaptic memory by using different random weights in the two environments, the number fell to $22.1 \%$. Thus, at least part of the effect observed by Leutgeb et al. (2007) can be accounted for by the fact that some cells have stronger synapses than others. To specifically test this explanation of our simulations, we computed the average synaptic strength and found that it was stronger in cells that were winners in both environments $(0.134)$ than in cells that were not $(0.124)$.

In making all the simulations in our study, we considered a realistic number of inputs to the granule cell, but simulated the E\%-max winner-take-all process using only small fraction of granule cells (typically 4500 of a million). We investigated whether this lack of realism affected our results. We quantified the number of place fields as we varied the number of granule cell from 500 to 5000 (Fig. 8). As can be seen, when the number of granule cells was $>3000$, there was no further effect on the number of place fields. Thus, the 4500 granule cells we have used in simulations are sufficient to accurately capture the competitive process. 
The size of the granule cell EPSC generated by grid cell inputs It has not been previously possible to calculate the excitatory input to a cell in vivo from the properties of the input. The great deal of information that is known about the firing of grid cells and their synaptic connection to dentate granule cells provides a unique opportunity to do so. To achieve this goal, the first question that had to be addressed is how many presynaptic axons are active when the rat is in the place field of a granule cell. From the spatial distribution of firing of grid cells (Fig. 1), one can define the area around the vertex in which the majority $(80 \%)$ of action potentials occurs. We calculate that this region constitutes $\sim 38 \%$ of the total area. Thus, at any one position, $\sim 460$ of the 1200 inputs to granule cells will contribute.

The effectiveness of these 460 inputs in triggering the firing of the postsynaptic cell requires that we consider their timing; only inputs that are simultaneously active within the integration time of the granule cell membrane are relevant. We take as the integration time the membrane time-constant $[\sim 30 \mathrm{~ms}$; as determined using the whole-cell configuration of the patch-clamp technique (Schmidt-Hieber et al., 2008)]. Given that the average firing rate of grid cells is $\sim 10 \mathrm{~Hz}$ over the vertexes of grids (E. Moser, personal communication), the average spike separation $(100 \mathrm{~ms})$ is somewhat longer than the integration time. From this we conclude that the probability of a spike within the integration period is $\sim 0.4$. It follows that $\sim 180$ input axons will be active during an integration period.

However, because the generation of a postsynaptic response at individual synapses is probabilistic, not every action potential will generate a postsynaptic response. The probability of transmission varies dramatically from synapse to synapse (Malinow et al., 1994) and is related to synapse size (Schikorski and Stevens, 1997; Murthy et al., 2001), which varies $>20$-fold (Fig. 6 B). One estimate of the average probability of transmission in dentate granule cells comes from measurement of the probability of a postsynaptic response in response to minimal stimulation (the activation of a single axon). By this technique, the average probability of response is 0.45 in granule cells (Min et al., 1998). However, minimal stimulation may slightly overestimate the probability of response of a single synapse because axons can sometimes make multiple synapses with their target. Indeed, work on granule cells shows that the nonfailure response amplitude evoked by minimal stimulation can be reduced slightly by lowering response probability in low $\mathrm{Ca}^{2+}$ (Bekkers and Clements, 1999), a result that indicates that a small fraction of axons indeed make multiple synapses with individual granule cells. A method that avoids this problem is the measurement of the probability of a presynaptically evoked $\mathrm{Ca}^{2+}$ response within a single spine, a method that in CA1 yields an average probability of transmission of 0.3 (Emptage et al., 2003). Assuming this value applies to granule cells, we conclude that of the 150 synapses at which an action potential occurs within the integration period, only $\sim 50$ will release a synaptic vesicle and produce a postsynaptic response.

The current produced by these 50 synapses can be estimated from the measured charge flow during the quantal response. In voltage-clamped granule cells, the average miniature (mEPSC) amplitude is $\sim 5 \mathrm{pA}$ (Bekkers and Clements, 1999) and the AMPA current falls with a time-constant of 5-6 ms. Thus, $\sim 0.025 \mathrm{pC}$ enters through AMPA channels during a mEPSC. It follows that if 50 synapses release a vesicle, the integrated EPSC will be $\sim 1 \mathrm{pC}$. In addition to this AMPA-mediated component, there will be charge entry through the NMDA channel. These channels are largely, but not completely blocked near resting potential; exper- iments in dentate granule cells (Keller et al., 1991) indicate that although the NMDAR current is small, it is long enough to produce a charge entry slightly larger than that through the faster AMPAR. We thus estimate that the total charge generated by AMPA and NMDA channels will be 2-3 pC. This value can be compared with the amount of charge needed to bring the granule cell to threshold, which can be derived from the current injection [Geiger and Jonas (2000), their Fig. $2 D b$ ], and is $\sim 1$ pC. We conclude that the excitatory input from the medial entorhinal cortex is somewhat larger, but not massively larger, than required to reach the threshold of granule cells.

\section{Discussion}

We have used simulation methods to examine how the inputs from entorhinal grid cells can result in the formation of place fields in dentate granule cells. We have taken into consideration the great deal of anatomical and physiological information about the synaptic connections involved. Place fields were computed by summing the input of 1200 synapses made by the grid cells onto granule cells. The entorhinal input to each synapse was chosen randomly from 10,000 grid cells of varying spatial frequency and phase. The strength of synapses can be highly variable (20-fold), and this was taken into consideration. Once the excitation maps of granule cells were computed, they were subject to an $\mathrm{E} \%$-max winner-take-all process governed by gamma frequency feedback inhibition (de Almeida et al., 2009); at each position, the cells that fire are those having excitation within $10 \%$ of the cell with maximum excitation. Using this procedure, which has no freely adjustable parameters, we found that computed place fields have strong similarities to actual place fields. Specifically, the area of computed place fields is in good agreement with experimental data. Furthermore, granule cells can have multiple place fields $(\sim 2)$ and our estimate of 1.5 is probably within experimental error. We furthermore found that a large percentage $(75 \%)$ of simulated granule cells has no place fields at all; similarly, a large fraction (possibly a larger fraction) of actual granule cells has no place fields. Our main conclusion is that the place fields of granule cells can be largely accounted for by the summation of inputs from randomly selected grid cells, the contribution of synapse strength variability, and the interaction of excitation with gamma frequency inhibition. Thus, to a first approximation, learning is not required for the formation of place fields. This conclusion stands in contrast to previous, less realistic simulations (see below), which led to the conclusion that place field formation is strongly dependent on synaptic plasticity. Our findings do not exclude a minor role for plasticity; indeed, it is known that synaptic plasticity is required to enhance the long-term stability of place cells (McHugh et al., 1996; Cho et al., 1998; Kentros et al., 1998), and some minor refinement of place cells properties during this process might well occur.

The proposal that place fields do not depend strongly on learning is consistent with several lines of other evidence: (1) Place cells are evident as soon as firing occurs in a new environment rather than developing slowly, as would be expected if place fields depended on plasticity (Hill, 1978; Wilson and McNaughton, 1993; Frank et al., 2004). (2) If place fields were learned, they should not be present in a novel environment if synaptic plasticity is blocked. Since the synapses of grid cells onto granule cells have the NMDAR-dependent form of LTP (Hanse and Gustafsson, 1992; Colino and Malenka, 1993), mice lacking NMDARs in the dentate should have relatively normal place fields. Such mice exist (McHugh et al., 2007; Niewoehner et al., 2007), but their place field properties have not yet been reported. However, ex- 
periments in which NMDARs are absent or nonfunctional have been performed in CA1, a region where place fields are also driven by grid cell input (Brun et al., 2008). It was found that CA1 place fields are nearly normal (McHugh et al., 1996; Kentros et al., 1998) in the absence of NMDARs. It might be argued that the existence of NMDARs in granule cell synapses is itself suggestive of involvement in place field formation; however, there are other potential functions of such receptors, notably to associate the inputs from the lateral and medial entorhinal cortex that converge onto granule cells (Lisman et al., 2007). (3) If, contrary to our model, place fields are learned by modification of excitatory synapses, then excitatory input should come to have a spatial distribution that closely matches the place field itself. Therefore, it should be difficult to make the cell fire outside of their place fields. In contrast, if the excitatory input distribution is spatially broad, and firing is focused by inhibition, then pharmacological agents that decreased the ratio of inhibition to excitation could potentially make firing maps broad. Perhaps consistent with this latter possibility, there is at least one known perturbation (scopolamine) that can greatly broaden place fields (Brazhnik et al., 2004). A more direct test of the properties of excitatory input would be to measure it directly by intracellular recording. Recently this kind of measurements has been done in CA1 in awake behaving rats. It was found that the spatial tuning of subthreshold depolarization in CA1 is very broadly tuned and that depolarization increases only modestly as the rat passes through the place field of the cell (Lee et al., 2008). These results are consistent with the idea that narrow place fields arise by a process that converts small differences in excitatory drive into large differences in firing rates. A related conclusion follows from analysis of orientation selectivity (de Almeida et al., 2009).

According to the theory we have developed, excitation is not only broadly tuned but, by itself, exceeds threshold over broad spatial regions; what usually keeps the voltage below threshold is gamma-frequency inhibition. As each cycle of inhibition wanes, it creates a rising ramp in principal cells. As the ramp progresses, the most excitable cells reach threshold and fire. These then set in motion the feedback inhibition that terminates further firing and initiates the next gamma cycle (de Almeida et al., 2009). Excitatory input to dentate granule cells has not yet been measured, but the dentate granule cells provide a unique situation for accurately calculating it. This is because the firing properties of the presynaptic cells in the medial entorhinal cortex have been well characterized, because the number of inputs from these cells to granule cells is known, and because there is detailed physiological analysis that allows estimation of the average postsynaptic charge produced by a presynaptic spike. Based on these data, we estimate that the excitatory input charge from the medial entorhinal cortex is $2-3$ times greater than necessary to reach threshold. Two testable predictions that follow from this conclusion are (1) that spiking in the dentate gyrus would be enormously increased by blocking inhibition and (2) that the medial entorhinal input is sufficient to fire granule cells; thus, a depolarizing tone from the other major input to dentate granule cells (from the lateral entorhinal cortex) may occur, but is not required.

Our simulations provide insight into the factors required to correctly analyze place field formation. There appears to be no shortcut to account for the excitatory drive to granule cells; each input must be considered. The reason for this is straightforward. Place field formation depends on a compromise between two factors. On the one hand, many cells must summate so that that the receptive field of the granule cell does not display the spatially broad and periodic properties of grid cells. On the other hand, if too many inputs summate, the excitation map will be so flat (an inevitable consequence of averaging) that all cells will satisfy the E\%-max requirement and do so at all positions; in this case firing will occur over the entire environment, contrary to observation. The existing number of inputs can be seen as a compromise between these extremes. It follows that to simulate place cell formation one must use the actual number of inputs. Moreover, since many synapses are extremely weak, the effective number of inputs is less than the actual number. It is thus necessary to take into consideration the large variability in synaptic strength.

Since the identification of grid cells (Fyhn et al., 2004; Hafting et al., 2005), many computational models have addressed their function. Some efforts have concentrated on the role of grid and place fields in navigation (Gaussier et al., 2007; Guanella and Vershure, 2007; Guanella et al., 2007). Other models have focused, as we have done, on how place fields are formed from grid cells (Rolls et al., 2006; Solstad et al., 2006; Franzius et al., 2007; Hayman and Jeffery, 2008; Molter and Yamaguchi, 2008). These studies have concluded that place field formation relies strongly on synaptic plasticity, contrary to our conclusions. This difference, we believe, occurs because we have used a dynamic form of feedback inhibition (as occurs in hippocampal neurons) and because we have realistically modeled the actual number of synapses involved. An important next step in the modeling of hippocampal place fields will be to account for additional factors, notably the theta phase precession of place cells (O'Keefe, 1976) and the nonspatial input that comes from the lateral entorhinal cortex.

In summary, we argue that the input-output transformation of dentate granule cells occurs largely by simple summation of randomly chosen excitatory inputs from grid cells, in conjunction with a highly effective winner-take-all process mediated by gamma-frequency feedback inhibition. Because this feedback process depends on properties of the network, the formation of place cells must be viewed not as a single cell process, but as a network process. This is a very fundamental point, but can be counterintuitive. It is tempting to view the hills and valleys of the excitation landscape of individual cells (Fig. 5) and to think that interaction with inhibition will make the highest peaks the location of place fields. This, however, is not correct: there is no process that compares excitation at different positions (to which the rat comes at different times). Rather, our results suggest that a cell has a place field when its excitation at that place (and time) is greater than that of other cells in the network. We propose that the required cross-cell comparison is a network process performed by gamma-frequency inhibition. Given the occurrence of these oscillations in many brain regions, receptive field formation by this mechanism may be of general importance.

\section{References}

Alle H, Jonas P, Geiger JR (2001) PTP and LTP at a hippocampal mossy fiber-interneuron synapse. Proc Natl Acad Sci U S A 98:14708-14713.

Bartos M, Vida I, Frotscher M, Meyer A, Monyer H, Geiger JR, Jonas P (2002) Fast synaptic inhibition promotes synchronized gamma oscillations in hippocampal interneuron networks. Proc Natl Acad Sci U S A 99:13222-13227.

Bekkers JM, Clements JD (1999) Quantal amplitude and quantal variance of strontium-induced asynchronous EPSCs in rat dentate granule neurons. J Physiol 516:227-248.

Blair HT, Welday AC, Zhang K (2007) Scale-invariant memory representations emerge from moire interference between grid fields that produce theta oscillations: a computational model. J Neurosci 27:3211-3229.

Bragin A, Jandó G, Nádasdy Z, Hetke J, Wise K, Buzsáki G (1995) Gamma $(40-100 \mathrm{~Hz})$ oscillation in the hippocampus of the behaving rat. J Neurosci 15:47-60. 
Brazhnik E, Borgnis R, Muller RU, Fox SE (2004) The effects on place cells of local scopolamine dialysis are mimicked by a mixture of two specific muscarinic antagonists. J Neurosci 24:9313-9323.

Brun VH, Leutgeb S, Wu HQ, Schwarcz R, Witter MP, Moser EI, Moser MB (2008) Impaired spatial representation in CA1 after lesion of direct input from entorhinal cortex. Neuron 57:290-302.

Chawla MK, Guzowski JF, Ramirez-Amaya V, Lipa P, Hoffman KL, Marriott LK, Worley PF, McNaughton BL, Barnes CA (2005) Sparse, environmentally selective expression of Arc RNA in the upper blade of the rodent fascia dentata by brief spatial experience. Hippocampus 15:579-586.

Cho YH, Giese KP, Tanila H, Silva AJ, Eichenbaum H (1998) Abnormal hippocampal spatial representations in alphaCaMKIIT286A and CREBalphaDelta- mice. Science 279:867-869.

Colino A, Malenka RC (1993) Mechanisms underlying induction of longterm potentiation in rat medial and lateral perforant paths in vitro. J Neurophysiol 69:1150-1159.

Csicsvari J, Jamieson B, Wise KD, Buzsáki G (2003) Mechanisms of gamma oscillations in the hippocampus of the behaving rat. Neuron 37:311-322.

de Almeida L, Idiart M, Lisman JE (2009) A second function of gamma frequency oscillations: an E\%-max winner-take-all mechanism selects which cells fire. J Neurosci 29:7497-7503.

Emptage NJ, Reid CA, Fine A, Bliss TV (2003) Optical quantal analysis reveals a presynaptic component of LTP at hippocampal Schafferassociational synapses. Neuron 38:797-804.

Frank LM, Stanley GB, Brown EN (2004) Hippocampal plasticity across multiple days of exposure to novel environments. J Neurosci 24:7681-7689.

Franzius M, Vollgraf R, Wiskott L (2007) From grids to places. J Comput Neurosci 22:297-299.

Fyhn M, Molden S, Witter MP, Moser EI, Moser MB (2004) Spatial representation in the entorhinal cortex. Science 305:1258-1264.

Gaussier P, Banquet JP, Sargolini F, Giovannangeli C, Save E, Poucet B (2007) A model of grid cells involving extra hippocampal path integration, and the hippocampal loop. J Integr Neurosci 6:447-476.

Geiger JR, Jonas P (2000) Dynamic control of presynaptic Ca(2+) inflow by fast-inactivating $\mathrm{K}(+)$ channels in hippocampal mossy fiber boutons. Neuron 28:927-939.

Geiger JR, Lübke J, Roth A, Frotscher M, Jonas P (1997) Submillisecond AMPA receptor-mediated signaling at a principal neuron-interneuron synapse. Neuron 18:1009-1023.

Guanella A, Vershure P (2007) Predition of the position of an animal base on populations of grid and place cells: a comparative simulation study. J Integr Neurosci 6:1-14.

Guanella A, Kiper D, Verschure P (2007) A model of grid cells based on a twisted torus topology. Int J Neural Syst 17:231-240.

Hafting T, Fyhn M, Molden S, Moser MB, Moser EI (2005) Microstructure of a spatial map in the entorhinal cortex. Nature 436:801-806.

Hama K, Arii T, Kosaka T (1989) Three-dimensional morphometrical study of dendritic spines of the granule cell in the rat dentate gyrus with HVEM stereo images. J Electron Microsc Tech 12:80-87.

Hanse E, Gustafsson B (1992) Long-term potentiation and field EPSPs in the lateral and medial perforant paths in the dentate gyrus in vitro: a comparison. Eur J Neurosci 4:1191-1201.

Harris KM, Fiala JC, Ostroff L (2003) Structural changes at dendritic spine synapses during long-term potentiation. Philos Trans R Soc Lond B Biol Sci 358:745-748.

Hayman RM, Jeffery KJ (2008) How heterogeneous place cell responding arises from homogeneous grids - a contextual gating hypothesis. Hippocampus 18:1301-1313.

Hill AJ (1978) First occurrence of hippocampal spatial firing in a new environment. Exp Neurol 62:282-297.

Johnston D, Amaral DG (1998) Hippocampus. In: The synaptic organization of the brain, Ed 4 (Shepherd GM, ed), pp 417-458. New York: Oxford UP.

Keller BU, Konnerth A, Yaari Y (1991) Patch clamp analysis of excitatory synaptic currents in granule cells of rat hippocampus. J Physiol 435:275-293.

Kentros C, Hargreaves E, Hawkins RD, Kandel ER, Shapiro M, Muller RV (1998) Abolition of long-term stability of new hippocampal place cell maps by NMDA receptor blockade. Science 280:2121-2126.

Kraushaar U, Jonas P (2000) Efficacy and stability of quantal GABA release at a hippocampal interneuron-principal neuron synapse. J Neurosci 20:5594-5607.

Lee AK, Epsztein J, Brecht M (2008) Whole-cell recordings of hippocampal CA1 place cell activity in freely moving rats. Soc Neurosci Abstr 34:690.22.

Leutgeb JK, Leutgeb S, Moser MB, Moser EI (2007) Pattern separation in the dentate gyrus and CA3 of the hippocampus. Science 315:961-966.

Lisman JE, Harris KM (1993) Quantal analysis and synaptic anatomy-integrating two views of hippocampal plasticity. Trends Neurosci 16:141-147.

Lisman JE, Raghavachari S, Tsien RW (2007) The sequence of events that underlie quantal transmission at central glutamatergic synapses. Nat Rev Neurosci 8:597-609.

Malinow R, Otmakhov N, Blum KI, Lisman J (1994) Visualizing hippocampal synaptic function by optical detection of $\mathrm{Ca} 2+$ entry through the N-methyl-D-aspartate channel. Proc Natl Acad Sci U S A 91:8170-8174.

Mann EO, Radcliffe CA, Paulsen O (2005) Hippocampal gamma-frequency oscillations: from interneurones to pyramidal cells, and back. J Physiol 562:55-63.

Matsuzaki M, Ellis-Davies GC, Nemoto T, Miyashita Y, Iino M, Kasai H (2001) Dendritic spine geometry is critical for AMPA receptor expression in hippocampal CA1 pyramidal neurons. Nat Neurosci 4:1086-1092.

Matsuzaki M, Honkura N, Ellis-Davies GC, Kasai H (2004) Structural basis of long-term potentiation in single dendritic spines. Nature 429:761-766.

McHugh TJ, Blum KI, Tsien JZ, Tonegawa S, Wilson MA (1996) Impaired hippocampal representation of space in CA1-specific NMDAR1 knockout mice. Cell 87:1339-1349.

McHugh TJ, Jones MW, Quinn JJ, Balthasar N, Coppari R, Elmquist JK, Lowell BB, Fanselow MS, Wilson MA, Tonegawa S (2007) Dentate gyrus NMDA receptors mediate rapid pattern separation in the hippocampal network. Science 317:94-99.

Miles R (1990) Synaptic excitation of inhibitory cells by single CA3 hippocampal pyramidal cells of the guinea-pig in vitro. J Physiol 428:61-77.

Min MY, Asztely F, Kokaia M, Kullmann DM (1998) Long-term potentiation and dual-component quantal signaling in the dentate gyrus. Proc Natl Acad Sci U S A 95:4702-4707.

Molter C, Yamaguchi Y (2008) Impact of temporal coding of presynaptic entorhinal cortex grid cells on the formation of hippocampal place fields. Neural Netw 21:303-310.

Muller RU, Kubie JL (1989) The firing of hippocampal place cells predicts the future position of freely moving rats. J Neurosci 9:4101-4110.

Murthy VN, Schikorski T, Stevens CF, Zhu Y (2001) Inactivity produces increases in neurotransmitter release and synapse size. Neuron 32:673-682.

Nafstad PHJ (1967) An electron microscope study on the termination of the perforant path fibres in the hippocampus and the fascia dentata. Z Zellforsch 76:532-542.

Niewoehner B, Single FN, Hvalby Ø, Jensen V, Meyer zum Alten Borgloh S, Seeburg PH, Rawlins JN, Sprengel R, Bannerman DM (2007) Impaired spatial working memory but spared spatial reference memory following functional loss of NMDA receptors in the dentate gyrus. Eur J Neurosci 25:837-846.

Nusser Z, Lujan R, Laube G, Roberts JD, Molnar E, Somogyi P (1998) Cell type and pathway dependence of synaptic AMPA receptor number and variability in the hippocampus. Neuron 21:545-559.

O'Keefe J (1976) Place units in the hippocampus of the freely moving rat. Exp Neurol 51:78-109.

Raghavachari S, Lisman JE (2004) Properties of quantal transmission at CA1 synapses. J Neurophysiol 92:2456-2467.

Rahimi O, Claiborne BJ (2007) Morphological development and maturation of granule neuron dendrites in the rat dentate gyrus. Prog Brain Res 163:167-181.

Ramirez-Amaya V, Marrone DF, Gage FH, Worley PF, Barnes CA (2006) Integration of new neurons into functional neural networks. J Neurosci 26:12237-12241.

Rolls ET, Stringer SM, Elliot T (2006) Entorhinal cortex grid cells can map to hippocampal place cells by competitive learning. Network 17:447-465.

Sargolini F, Fyhn M, Hafting T, McNaughton BL, Witter MP, Moser MB, 
Moser EI (2006) Conjunctive representation of position, direction, and velocity in entorhinal cortex. Science 312:758-762.

Schikorski T, Stevens CF (1997) Quantitative ultrastructural analysis of hippocampal excitatory synapses. J Neurosci 17:5858-5867.

Schmidt-Hieber C, Jonas P, Bischofberger J (2008) Action potential initiation and propagation in hippocampal mossy fibre axons. J Physiol 586:1849-1857.

Sik A, Penttonen M, Buzsáki G (1997) Interneurons in the hippocampal dentate gyrus: an in vivo intracellular study. Eur J Neurosci 9:573-588.

Solstad T, Moser EI, Einevoll GT (2006) From grid cells to place cells: a mathematical model. Hippocampus 16:1026-1031.

Tashiro A, Makino H, Gage FH (2007) Experience-specific functional mod- ification of the dentate gyrus through adult neurogenesis: a critical period during an immature stage. J Neurosci 27:3252-3259.

Trommald M, Hulleberg G (1997) Dimensions and density of dendritic spines from rat dentate granule cells based on reconstructions from serial electron micrographs. J Comp Neurol 377:15-28.

Wilson MA, McNaughton BL (1993) Dynamics of the hippocampal ensemble code for space. Science 261:1055-1058.

Witter MP (2007) The perforant path: projections from the entorhinal cortex to the dentate gyrus. Prog Brain Res 163:43-61.

Zhou Q, Homma KJ, Poo MM (2004) Shrinkage of dendritic spines associated with long-term depression of hippocampal synapses. Neuron 44: 749-757. 